\title{
Tamiflu: the battle for secret drug data
}

\begin{abstract}
Influenza drug oseltamivir has made billions of pounds for Roche, but why won't the company give patients and doctors access to the full clinical data? As part of the BMSs open data campaign, we this week launch a new site dedicated to the cause. David Payne reports
\end{abstract}

\section{David Payne editor, bmj.com}

BMJ, London WC1H 9JR

This week the $B M J$, as part of its ongoing open data campaign, has launched a dedicated website aimed at persuading Roche to give doctors and patients access to the full data on oseltamivir (Tamiflu).

The new site, www.bmj.com/tamiflu, displays emails and letters dating back to September 2009, when researcher Tom Jefferson first asked the company for the unpublished dataset used in a Roche supported analysis, published in $2003 .{ }^{1}$

Jefferson needed the data by the following month to update the Cochrane Collaboration's review on neuraminidase inhibitors in healthy adults. At first the company asked him to sign a confidentiality agreement promising that he would not publish the data in full. ${ }^{2}$

Then it declined to supply it on the grounds that it had been approached by an independent expert influenza group undertaking a similar meta-analysis and wanted to avoid a conflict. Roche added that its study reports had also been shared with the regulatory authorities.

Jefferson told the company in an email: "I recognise that more people than me are interested in reviewing the trials of interventions for influenza at the moment.

"But I don't understand why this should lead to exclusivity, or why you would believe that there would be a conflict between our plans to update our Cochrane review and the plans of the other research groups you mention."

Jefferson's October deadline passed. Two months later the Cochrane review, published in the $B M J{ }^{3}$ said that because eight of the 10 randomised controlled trials on which effectiveness claims were based were never published, the evidence could not be relied on. Also, the two published studies were funded by Roche and authored by Roche employees and external experts paid by Roche.

The review concluded: "Paucity of good data has undermined previous findings for oseltamivir's prevention of complications from influenza. Independent randomised trials to resolve these uncertainties are needed."

An accompanying $B M J$ investigation and analysis article described how Cochrane's attempt to reproduce an analysis underpinning the use of oseltamivir in pandemic flu hit a brick wall. $^{45}$

In December 2009 Roche promised to make full study reports on the 10 trials available to doctors and scientists. ${ }^{6}$ But this October $B M J$ editor in chief Fiona Godlee reminded the company, in a letter to board member John Bell, that Roche had still not made the full clinical study reports available. ${ }^{2}$

She told him: "Tamiflu has been a huge commercial success for Roche. Billions of pounds of public money have been spent on it, and yet the evidence on its effectiveness and safety remains hidden from appropriate and necessary independent scrutiny.

"I am appealing to you as an internationally respected scientist and clinician and a leader of clinical research in the UK to bring your influence to bear on your colleagues on Roche's board."

Roche has yet to respond formally, but the email exchanges are now in the public domain at www.bmj.com/tamiflu for all to see.

All emails are loaded as jpeg images using the $B M J$ 's rapid response system and as pdfs. They are displayed in chronological order, and readers can join the debate by submitting comments, which will then be considered for publication. There is also an interactive timeline reminding readers of key developments in the oseltamivir story going back to the early days of the H1N1 influenza pandemic in 2009.

\section{Accountability}

www.bmj.com/tamiflu allows readers to witness attempts to compel greater accountability and responsibility in public health decision making and policy. The $B M J$ plans to launch other campaigns linked to its investigations in the future. 
Jefferson's colleague Peter Doshi, a postdoctoral fellow at Johns Hopkins University, Baltimore, describes bmj.com/tamiflu as the online equivalent of an open letter.

He said: 'I' $m$ not aware of anything that does more than just a simple open letter. The reader can see the correspondence almost as a stage play. One can see how the actors are actually acting, especially when one is pushing for accountability but the other party refuses to engage. If you make that kind of behaviour visible, perhaps you can actually achieve progress."

"For decades industry and regulators have worked largely under agreement-sometimes forced by law and other times just tacit agreements - that the data that would be shared between them would be confidential and treated as a trade secret.

"Now we're realising there is a number of enormously harmful consequences from those policies in which arguably drug disasters like Vioxx [rofecoxib] or Celebrex [celecoxib] or Avandia [rosiglitazone] could have been detected much earlier had the data been available."

Also listed is the Cochrane group's correspondence with the World Health Organization ${ }^{7}$ and the US Centers for Disease Control and Prevention (CDC). ${ }^{8}$

The WHO correspondence begins with an email from Jefferson in February 2012. He asks WHO scientists how its review process had led to it including oseltamivir in its March 2011 "essential medicines" list.

Had it asked the manufacturers of neuraminidase inhibitors for the unpublished trial data? Also, what had WHO scientists made of Cochrane's conclusion "that there is no evidence that oseltamivir can limit the spread of influenza."

WHO told Jefferson that it was currently developing a standard guideline on clinical management of influenza virus infection.

It had also commissioned several evidence reviews, including one on oseltamivir that was set to appear soon in a peer reviewed medical journal. It promised to alert Jefferson when the review appeared.

The email exchange with the CDC asked for written answers to six detailed questions in response to an article posted on its website on 7 February 2012, CDC Recommendations for Influenza Antiviral Medications Remain Unchanged. ${ }^{9}$

Why, for example, did the CDC not consider unpublished data? Had it asked Roche for any? Did it have any evidence that oseltamivir could stop the spread of influenza?

The CDC article maintained that reviews of randomised controlled trials might not fully inform the question of whether antiviral treatment reduces severe complications of influenza.

But is also maintained that "reviews of RCTs ... have found consistent clinical benefit of early oseltamivir treatment in reducing the risk of lower respiratory tract complications."

Neither Jefferson nor Doshi was impressed with the CDC's response, which they challenged in five follow-up emails.

Jefferson told the $B M J$ last week that the US Food and Drug Administration had described Tamiflu's effects as modest.

"Despite this, WHO and CDC have been extensively promoting the drug. WHO has made Tamiflu one of the essential drugs, so it sits next door to aspirin and penicillin, cortisone," he said. "The CDC has extensively recommended the use of Tamiflu, and, as you know, governments worldwide have stockpiled it on the advice, essentially, of WHO.

"We were trying to find out exactly what evidence these decisions were made on. So we asked questions, and we also asked WHO and CDC whether they'd seen our review and what their thoughts were.

"Readers will see the kind of stonewalling that we got. Indeed, my correspondence with WHO shows that they didn't answer a single one of my questions.

"Politicians have ignored the problem and have not demanded accountability from their own decision makers, from regulators, and from industry."

This could be about to change, in the UK at least. Last week Sarah Wollaston, a general practitioner and Conservative member of parliament, raised the issue of missing data in parliament. Health minister Norman Lamb has agreed to meet experts to discuss what he referred to as "the really important issue" of access to data from clinical trials. ${ }^{10}$

In an email telling Jefferson about the planned meeting, Wollaston said: "It will surely be a turning point in the campaign for open data if we can show that $£ 1$ in every $£ 200$ of the total NHS budget for 2009 was spent stockpiling a drug for which a drug company had knowingly concealed data either showing it had no real benefits ... or worse . . caused real harm."

Competing interests: The author has completed the ICMJE unified disclosure form at www.icmje.org/coi_disclosure.pdf (available on request from the corresponding author) and declares no support from any organisation for the submitted work; no financial relationships with any organisation that might have an interest in the submitted work in the previous three years; and no other relationships or activities that could appear to have influenced the submitted work.

Provenance and peer review: Commissioned; not externally peer reviewed.

1 Kaiser L, Wat C, Mills T, Mahoney P, Ward P, Hayden F. Impact of oseltamivir treatment on influenza-related lower respiratory tract complications and hospitalizations. Arch Intern Med 2003;163:1667-72.

2 Tamiflu email exchanges with Roche. www.bmj.com/tamiflu/roche.

3 Jefferson T. Neuraminidase inhibitors for preventing and treating influenza in healthy adults: systematic review and meta-analysis. BMJ 2009;339:b5106.

4 Cohen D, Carter P. WHO and the pandemic flu "conspiracies." BMJ 2010;340:c2912.

5 Doshi P. Neuraminidase inhibitors-the story behind the Cochrane review. BMJ 2009;339:b5164.

6 Smith J, on behalf of Roche. Point-by-point response from Roche to BMJ questions. BMJ 2009;339:b5374.

7 Tamiflu email exchanges with the World Health Organization www.bmj.com/tamiflu/who.

8 Tamiflu email exchanges with the Centers for Disease Control and Prevention www.bmj. com/tamiflu/cdc.

9 Centers for Disease Control and Prevention. Recommendations for influenza antiviral medications remain unchanged. www.cdc.gov/media/haveyouheard/stories/Influenza antiviral.html.

10 Kmietowicz $Z$. Health minister agrees to meet academics to discuss access to clinical trial data. BMJ 2012;345:e7168.

Cite this as: BMJ 2012;345:e7303

(c) BMJ Publishing Group Ltd 2012 


\section{Tamiflu timeline}

October 1997: The US Food and Drug Administration approves oseltamavir for the treatment of influenza in adults

May 2002: WHO, with partners, develops a new global agenda on influenza surveillance and control. Part of the guidance includes country level stockpiling of antiviral drugs to treat influenza

July 2005: Kaiser and colleagues publish their meta-analysis of the effect of oseltamivir on flu related lower respiratory tract complications. The review contained unpublished data from the manufacturer, Roche

October 2005: As avian influenza H5N1 spreads globally, the United Nations warns a pandemic could lead to between five million and 150 million deaths

July 2006: The Cochrane Collaboration carries out its first review-including data from the Kaiser meta-analysis-into the use of neuraminidase inhibitors (NIs) for preventing and treating influenza in healthy adults. They conclude that "Because of their low effectiveness, Nls should not be used in routine seasonal influenza control. In a serious epidemic or pandemic, Nls should be used with other public health measures."

March 2009: H1N1 influenza ("swine flu") emerges in Mexico and spreads globally

June 2009: WHO declares a flu pandemic. The H1N1 subtype had also caused the 1918 flu pandemic, which had a death rate of about $10 \%$, raising fears that the death toll in the new pandemic would be measured in millions. Following WHO guidelines, governments worldwide start to stockpile oseltamivir, spending \$6.9bn (2009 value)

July 2009: Japanese paediatrician Keiji Hayashi contacts the Cochrane Collaboration with questions about the Kaiser meta-analysis. He points out that the review was based on unpublished, un-peer reviewed data from Roche given in confidence to the authors

October 2009: Tom Jefferson, from the Cochrane Collaboration, requests data from Roche. It offers the data, but on the proviso that an agreement is made of confidentiality not only of the data but of the agreement itself. Cochrane declines

December 2009: $B M J$ missing data cluster. The $B M J$ calls for Roche to make all its data available for scientific scrutiny. At the same time an investigation into conflicts of interest within WHO is published, showing links between those creating the guidelines for pandemic flu planning and Roche. The Cochrane team re-analyses the data from its previous meta-analysis, excluding the data shared with Kaiser by Roche. The team find no evidence to suggest that oseltamivir reduces complications in cases of influenza

January 2011: Cochrane Collaboration approaches the European Medicines Agency to obtain the data it used as the basis of the approval of oseltamivir

April 2011: The European Medicines Agency sends 25453 pages of clinical study reports to the Cochrane Collaboration

October 2012: Data from Roche are still undisclosed, despite assurances that the company would open them up to scientific scrutiny 